\title{
Mid basilar artery aneurysm presenting as meningitis in a 6 years old child
}

\author{
Neeraj Awasthy*, Kislay Shrivastava and Jeevan Jot Chauhan Karam Chand \\ Department of Pediatric Cardiology, Max Super specialty Hospital, New Delhi-110017, India and Department of Neurosurgery, Safdarjung Hospital, Delhi, India
}

\begin{abstract}
We present a case report of mid basilar aneurysm in a 6-year-old child which is a rare anomaly in this age group. The child presented with acute onset altered sensorium with history of mild fever. On examination the child had spontaneous eye movement, localized pain but had no verbal response. Child had neck stiffness. Meningitis was suspected. NCCT head revealed hydrocephalus and subarachnoid hemorrhage and a bleed in front of brainstem. He underwent ventriculoperitoneal medium pressure shunt was done. CT angio revealed mid basilar aneurysm and the aneurysm was clipped through left retro mastoid approach. Child is doing well.
\end{abstract}

\section{Introduction}

Intracranial aneurysms are very rare in children and adolescents. The literature itself is very scant on intracranial aneurysms in pediatric population $[1,2]$.

\section{Case details}

A 6 years old child presented with history of mild fever since last 3 days and acute onset altered sensorium which made the child bed ridden and child had to be fed through Ryle's tube and the child was referred to our hospital for further management. there was history of mild fever. On examination child had heart rate of 80 beats per minute, a blood pressure of 110/80 $\mathrm{mm}$ hg in right upper limb; he opened eyes spontaneously, localized pain but had no verbal response. Child had neck stiffness and meningitis was suspected. He had neurological status of E4V1M6. NCCT head revealed hydrocephalus due to obstruction at the level of foramen of Monroe and subarachnoid hemorrhage and a bleed in front of brainstem (Figure 1). A right ventriculoperitoneal medium pressure shunt was done. CT angio revealed mid basilar

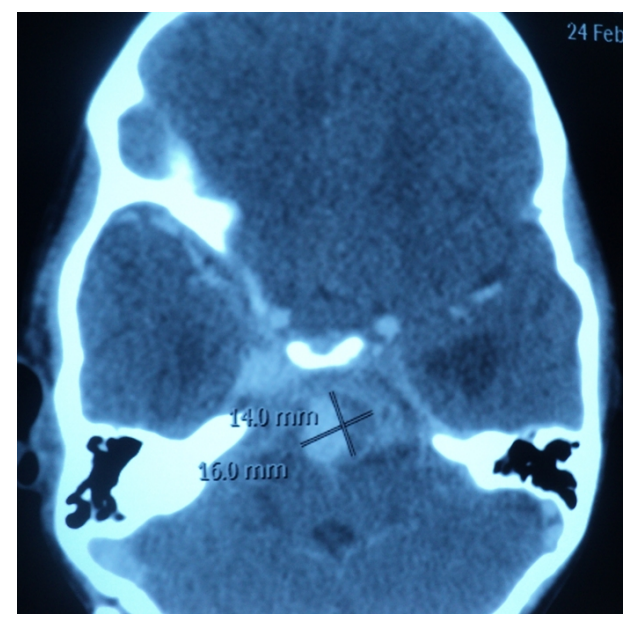

Figure 1. NCCT head revealed at the level of the brainstem showing the subarachnoid hemorrhage $14 \times 16 \mathrm{~mm}$ (marked by arrow) aneurysm. The aneurysm was clipped through left retro mastoid approach. Child is doing well.

\section{Discussion}

The incidence of aneurysmal hemorrhage is about $0.05-0.09$ per 100000 person-years in children younger than 15 years which is 35 times lower than in adults [3]. Incidence of intracranial aneurysm according to sex is also different than adults; while in adults occur twice as often in females than in males [4]. In children it is observed to be a male to female ratio of 3:2, however, the ratio became 1:5 for children younger than 2 years [5]. Most common presenting symptom of intracranial aneurysms is Subarachnoid hemorrhage (SAH) which is the predominant mode of presentation in adults and children [6,7]. There has been significantly less number of cases reported in pediatric population as compared to adults. Clinical features range from asymptomatic to deep coma. Or child presented with features of meningismus which has not been reported. Surgical clipping of basilar trunk aneurysms is technically challenging and risky owing to complexity and structures surrounding aneurysm.Endovascular occlusion is now at a forefront of managing basilar aneurysms. Children have lower incidence of hemorrhagic presentation due to the high incidence of giant aneurysms with mass effect rather than hemorrhagefrom the aneurysm with neurological manifestations which is as high as $46 \%$ in the patient [8]; $17 \%$ of the children presented with neurological deficits and/or epilepsy, whereas in another $8 \%$ the aneurysm was found in the diagnostic work-up for chronic headaches. The rate of incidental diagnosis was as high as $35 \%$ as mentioned by Kakarla et al. [9]. seizures in pediatric patients has been reported to be more than twice of that in adults (36\% versus $17 \%$, respectively. Also, acute hydrocephalus was seen more often in children (36\%) than in adults (25\%) [10]. Posterior circulation aneurysms are more common in children with a rate of $21 \%$, which corresponds to

${ }^{\star}$ Correspondence to: Neeraj Awasthy, Department of Pediatric Cardiology, Max Super specialty Hospital, Saket, New Delhi-110017, India, Tel: +919811962775; E-mail: n_awasthy@yahoo.com

Received: May 08, 2018; Accepted: July 19, 2018; Published: July 23, 2018 
almost three times the incidence found in adults. Vertebral artery aneurysms comprise 5\% in children. Likewise, aneurysms were found in $11,4 \%$ on the basilar artery in children $(7,6 \%$ basilar artery $+3,8 \%$ basilar termination), but only in $4-8 \%$ in adults, respectively [11]. We report such rare mid basilar artery aneurysm presenting as meningitis on account of age of presentation, mode of presentation and site of presentation .It should be noted that the rarity of the intracranial aneurysm in children at such a young age makes primary consideration of aneurysm as a cause of such symptoms of fever with neurological symptoms with meningeal irritation unlikely leading to delay in diagnosis. Endovascular treatment with coils or coiling through a stent may not accomplish life-long occlusion of the aneurysm as is intended in adult population. Furthermore, endovascular procedures are difficult to perform in the youngest children. Also, there is a higher rate of rebleeding of ruptured aneurysms in children than in adults which may affect the outcome dramatically to the worse [6].

\section{References}

1. Sorteberg A, Dahlberg D (2013) Intracranial non-traumatic aneurysms in children and adolescents. Current Pediatric Reviews 9: 343-352. [Crossref]

2. Hetts SW, Narvid J, Sanai N, Lawton MT, Gupta N, et al. (2009) Intracranial aneurysms in childhood: 27-year single-institution experience. AJNR Am J Neuroradiol 30: 13151324. [Crossref]
3. Jordan LC, Johnston SC, Wu YW, Sidney S, Fullerton HJ (2009) The importance of cerebral aneurysms in childhood hemorrhagic stroke: a population-based study. Stroke 40: 400-405. [Crossref]

4. Søfteland SM, Romundstad R, Müller TB, Vatten L, Vik A. (2009) Risk factors for aneurysmal subarachnoid hemorrhage in a prospective population study. The HUNT Study in Norway. Stroke 40:1058-1062. [Crossref]

5. Lasjaunias P, Wuppalapati S, Alvarez H, Rodesch G, Ozanne A (2005) Intracrania aneurysms in children aged under 15 years: review of 59 consecutive children with 75 aneurysms. Childs Nerv Syst 21:437-450. [Crossref]

6. Vaid VK, Kumar R, Kalra SK, Mahapatra AK, Jain VK (2008) Pediatric intracranial aneurysms: an institutional experience. Pediatr Neurosurg 44: 296-301. [Crossref]

7. Sanai N, Quinones-Hinojosa A, Gupta NM, Perry V, Sun PP, et al. (2006) Pediatric intracranial aneurysms: durability of treatment following microsurgical and endovascular management. J Neurosurg 104: 82-89. [Crossref]

8. Krings T, Geibprasert S, terBrugge KG (2010) Pathomechanisms and treatment of pediatric aneurysms. Childs Nerv Syst 26: 1309-1318. [Crossref]

9. Kakarla UK, Beres EJ, Ponce FA, Chang SW, Deshmukh VR, et al. (2010) Microsurgical treatment of pediatric intracranial aneurysms: long-term angiographic and clinical outcomes. Neurosurgery 67:237-250. [Crossref]

0. Krishna H, Wani AA, Behari S, Banerji D, Chhabra DK, et al. (2005) Intracrania aneurysms in patients 18 years of age or under, are they different from aneurysms in adult population? Acta Neurochir (Wien) 147: 469-476. [Crossref]

11. Weir B, Loch Macdonald R, Wilkins RH, Rengachary SS (1985) Intracranial aneurysms and subarachnoid hemorrhage: an overview. Neurosurgery 2: 2191-2213.

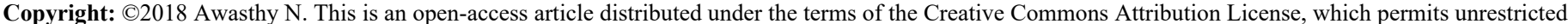
use, distribution, and reproduction in any medium, provided the original author and source are credited. 